\title{
A INDUSTRIALIZAÇÃO DAS EDITORAS E DOS LIVROS DIDÁTICOS NOS ESTADOS UNIDOS (DO SÉCULO XIX AO COMEÇO DO SÉCULO XX)
}

\author{
MIRIAN JORGE WARDE*
}

\begin{abstract}
RESUMO: Este artigo examina a implantação da indústria do livro didático nos Estados Unidos a partir da terceira década do século xix. Nos anos 20 daquele século, editoras sediadas na cidade de Nova York e em Boston já haviam adquirido a capacidade de editar diferentes modalidades de livros didáticos, além de livrinhos para diversão das crianças, e vendê-los em regiões distantes do país, para o que tiveram a iniciativa de destacar funcionários com dedicação exclusiva. Em fins daquela década, o processo de produção sofisticou-se com a organização e o treinamento de equipes para a escrita especializada dos schoolbooks. No rastro dessas primeiras casas editoriais, outras se afirmaram, tornando-se potências nacionais e internacionais ao desempenharem papel decisivo tanto na americanização das enormes levas de imigrantes que chegaram ao país, desde meados do século xIx, quanto na americanização dos povos submetidos ao domínio militar ou econômico dos EUA.
\end{abstract}

Palavras-chave: Livro didático. Editora. Editor. Industrialização. Estados Unidos.

\section{THE INDUSTRIALIZATION OF PUBLISHING HOUSES AND SCHOOLBOOKS IN THE USA (FROM THE $19^{\text {TH }}$ CENTURY TO THE BEGINNING OF THE $20^{\mathrm{TH}}$ CENTURY)}

ABSTRACT: This paper examines the establishment of the textbook industry in the United States from the third decade of the nineteenth century on. In the 1920s, publishers based in New York and Boston were already able to edit different types of textbooks and booklets for child amusement, and sell them in the farthest regions of the country, for which they took the initiative to deploy full time staff. At the end of that decade, the production process was improved by the organization and training of teams specialized in writing schoolbooks. In the wake of those first publishing houses, others settled and became national and international powers. They played a decisive role in the Americanization of the huge waves of immigrants who arrived in that country since the midnineteenth century as well as of the people submitted to the USA military or economic control.

Key words: Schoolbook. Publishing house. Publisher. Industrialization. United States.

\footnotetext{
* Doutora em Filosofia da Educação e professora visitante da Faculdade de Filosofia, Ciências e Le-
} tras da Universidade Estadual Paulista (UNEsP, Araraquara). E-mail: mjwarde@uol.com.br 


\section{L'INDUSTRIALISATION DES MAISONS D'EDITIONS ET DES LIVRES DidACTIQUES AUX ÉTATS-UNIS (DU XIXE SIECLE AUX DEBUTS DU XXE SIECLE)}

RÉSUMÉ: Cet article examine la création de l'industrie du livre didactique aux États-Unis à partir des années 30 du XIXe siècle. Dès les années 20 de ce siècle, des maisons d'éditions sises dans les villes de New York et Boston étaient déjà capables de publier différents types de livres didactiques et de petits livres pour enfants et de les vendre aux quatre coins du pays, où elles avaient détaché des fonctionnaires pour ce faire. À la fin de cette décennie, le processus de production s'est sophistiqué avec l'organisation et l'entraînement d'équipes spécialisées dans l'écriture de schoolbooks. Dans le sillage de ces premières maisons d'éditions, d'autres se sont affirmées et sont devenues des puissances nationales et internationales jouant un rôle décisif aussi bien dans l'américanisation des énormes vagues d'immigrants qui sont arrivées dans ce pays, dès la moitié du XIXe siècle, que dans celle des peuples soumis à la domination militaire ou économique des EUA.

Mots-clefs: Livre didactique. Maison d'édition. Industrialisation. États-Unis.

\section{Introdução}

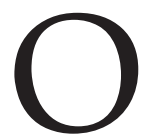

s catálogos organizados e publicados pelo livreiro norte-americano desde o começo do século XIX são bons indicadores do destacado lugar que editores e livreiros se reservavam na recém-instalada república norte-americana. De 1820 a 1861 puseram em circulação a Bibliotheca Americana (Roorbach, 1939), que catalogou os impressores existentes, e, em seguida, The American Catalogue of Books (Kelly, 1866-1871), que manteve atualizadas as listas de livros originais e reeditados de 1861 a 1871 .

A partir de 1872, um editor de nome Frederick Leypoldt deu continuidade ao American Catalogue (de 1876 a 1910), além de ter lançado, na cidade de Nova York, o Publishers' Weekly, mantido até hoje. Em 1873, Leypoldt deu início à lista anual do movimento livreiro nos eua por meio da Publishers' Trade List Annual (PTLA), na qual incluía a lista completa dos editores norte-americanos e dos livros publicados a cada ano, acompanhados dos títulos, autores, preços e procedimentos para encomenda. Em acréscimo, H. W. Wilson Co. iniciou, em 1898, o Cummulative Book Index (Goodrich, 1856; Kurian, 1975; Lehmann-Haupt et al., 1951).

Alimentadas e editadas com regularidade, essas listagens anuais projetaram nacionalmente e instrumentaram internacionalmente os editores e livreiros norteamericanos em suas persistentes investidas com vistas à criação de mercado consumidor global. Bem organizados e com um grau razoável de união, eles se tornaram presença destacada nas exposições internacionais, ao menos desde a de Paris, em 1867, atraindo para si parte das atenções antes centradas nas engenhosas máquinas de seus compatriotas. Foram, por isso mesmo, grandemente responsáveis pela 
rendição europeia às iniciativas escolares e acadêmicas norte-americanas. Sobre as reações europeias às exibições norte-americanas, diz Curti (1950, p. 852):

As promissoras e atraentes exibições em Paris, no ano de 1867, e em Viena, de 1873, prepararam os europeus para o que se efetivou em Paris, em 1878. Em torno de 200 exibidores ofereceram um quadro satisfatório da educação norte-americana, com ilustrações de prédios, mobiliário, equipamentos e aparatos educacionais; com 2.500 volumes de literatura educacional (...) e 400 volumes de trabalhos de estudantes primários e superiores. Ganharam vários prêmios. A superioridade norte-americana em livros didáticos foi generalizadamente admitida (...). Os catálogos das firmas indicavam que os editores bem representados e que o trabalho das bibliotecas haviam atraído a atenção dos europeus. Pela primeira em todas as exposições estrangeiras, ficou claro que as conquistas da cultura norte-americana não mais poderiam ser ignoradas.

As pesquisas consultadas reservam às editoras e às firmas de comercialização de impressos um dos lugares centrais na construção e difusão da moderna cultura norte-americana, industrial e urbana, e um papel decisivo na criação, impressão e reprodução em série da imagem modelar dos EuA para consumo interno e externo (Leonor, 1996; Pierce, 1926).

Ao mesmo tempo em que era alimentado por outros setores econômicos estratégicos, o ramo editorial teria revolucionado a cultura norte-americana ao transformar as técnicas de impressão e de fabricação do papel, impulsionando, assim, a criação dos magazines tanto quanto a reinvenção do jornal e a dessacralização do livro, convertendo-o em produto de massa (Pasko, 1894; Jennett, 1951; Strauss, 1967).

Para os historiadores da política interna norte-americana pós-colonial, o primeiro sinal de que aos impressores e editores estava reservado proeminente papel na construção da nova nação fora emitido pelos congressistas de 1791 que ratificaram a Constituição da União dos Estados Americanos e aprovaram as suas dez primeiras emendas, garantindo na primeira o direito à liberdade de imprensa (Winterich, 1935).

\section{A geografia editorial}

Da independência até meados do século xIx, a indústria e o mercado de impressos norte-americanos realizaram o primeiro ciclo de crescimento: entre $1820 \mathrm{e}$ 1852, em seis dos principais polos editoriais, foram registradas 762 firmas, sendo que $345(45,3 \%)$ só na cidade de Nova York, onde estava sendo montado o maior parque industrial no ramo, posição que a cidade sustentou por mais de um século. A ela seguiam, com razoável distância, dois outros importantes centros: Filadélfia (Pensilvânia) com 198 firmas e Boston (Massachusetts) com 147; completando a lista, duas cidades que despontavam lentamente para, ao final do século, incluir-se 
entre os dez primeiros polos editores dos EuA: Baltimore (Maryland), com 32, e Cincinnati (Ohio), com 25. Por fim, Charleston (Carolina do Sul), com 15 firmas, que logo sairia do mapa livreiro.

\section{Tabela}

Firmas editoriais por cidades com maiores concentrações (1820-1852)

\begin{tabular}{|c|c|c|}
\hline Cidades & Firmas & \% \\
\hline Nova York & 345 & 45,3 \\
\hline Filadélfia & 198 & 25,9 \\
\hline Boston & 147 & 19,3 \\
\hline Baltimore & 32 & 4,2 \\
\hline Cincinnati & 25 & 3,3 \\
\hline Charleston & 15 & 2 \\
\hline
\end{tabular}

Fonte: Roorbach (1939).

Com essa distribuição, estavam indicadas as principais tendências que se afirmariam até final do século xIx e se manteriam por quase todo o século seguinte; dentre essas tendências, interessa destacar:

- a ascensão dos EUA à liderança mundial no ramo editorial;

- a maior concentração da indústria e do mercado livreiros na região nordeste dos euA, com destaque aos estados de Nova York, Pensilvânia e Massachusetts;

- a segunda maior concentração no centro-oeste, que já estava indicada pela presença de Cincinnati, em meados do século xIx, e a entrada de Chicago (Illinois), pouco depois, no rol dos maiores centros editoriais do país;

- o crescimento vertiginoso dos impressos de destinação escolar, com destaque aos didáticos, denominados schoolbooks ou textbooks que, desde os anos 20 do século XIX, já suplantavam as demais modalidades de publicações encadernadas (Goodrich, 1856; Lehmann-Haupt et al., 1951; Elson, 1959, 1964).

Em fins do século XIX, as cidades de Nova York, Boston, Filadélfia e Chicago ocupavam mais da metade do mapa editorial dos EuA; em 1910, somavam em torno de $70 \%$ dos títulos produzidos e comercializados; Nova York, na liderança, respondia, isoladamente, por em torno de $40 \%$.

Embora fosse a maior e mais diversificada praça editorial, responsável pelas maiores transformações nas técnicas de impressão, de modernização do jornalismo 
e pelo maior espectro de magazines, a cidade de Nova York não concentrava as editoras especializadas. Ou seja, as firmas dedicadas a determinados assuntos ou a certos tipos de impressos estavam distribuídas pelo país e, em alguns campos específicos, alojavam-se em pequenas cidades.

Para Lehmann-Haupt et al., esse perfil generalista não seria exclusivo de Nova York, e sim uma característica de toda indústria e mercado editoriais dos EUA. Diz ele:

Os editores europeus, de modo geral, ainda mantêm firmas que cultivam algum assunto ou grupo de assuntos bem-definidos, amadurecidos ao longo de várias tradições (...). Há, antes de tudo, o verdadeiro editor-literato que reúne em torno de si um grupo definido e consagrado de escritores com o qual ele mantém um contato estreito (...). Nos Estados Unidos, ao contrário, uma ampla parcela de importantes firmas é composta de editores genéricos. Eles erguem seus negócios publicando em muitos campos, não importa o sucesso pretendido (...). A grande maioria das firmas do séc. XIX, nos EUA, incluía em suas listas: romances, biografias, viagens, poesias, ciência popular, livros infantis e, é claro, magazines. (LehmannHaupt et al., 1951, p. 212-223)

No que tange aos livros didáticos, Cincinnati foi o maior centro produtor até meados do século xIX, quando Boston e Filadélfia, nessa ordem, se tornaram as duas maiores praças nessa modalidade.

As casas editoriais de Boston, que se firmaram com os impressos didáticos organizados em séries e produzidas em larga escala, ganharam renome pelos materiais destinados às Sunday Schools, ${ }^{1}$ além da criação de novos tipos de literatura para o lazer e a diversão de crianças e jovens (Carpenter, 1963).

Na segunda metade do século XIX, dentre muitas outras firmas sediadas em Boston, se destacaram nas modalidades acima indicadas: a Lee \& Shepard responsável por uma grande lista de livros infantis, manuais de Inglês e Literatura Americana, hinos nacionais e músicas folclóricas, além do seu enorme sucesso com os títulos das Sunday Schools. A D. Lothrop \& Co., que também havia capitalizado as demandas das escolas dominicais, especializou-se em literatura para jovens. No início do século xx, as duas editoras, Lee \& Shepard e D. Lothrop \& Co., fundiram-se para formar a Lothrop, Lee and Shepard Co.

Em Boston foram criadas, também, duas outras editoras que rapidamente se tornaram proeminentes firmas especializadas em livros e outros impressos escolares: a Ginn Brothers, criada em 1867 pelos irmãos Edwin e Frederick. Foi a primeira empresa editorial norte-americana a lançar obras clássicas para crianças; com a série Classics for children, comercializada a partir de 1883, a editora colocou em circulação títulos tais como: Robinson Crusoé, Plutarch's lives e outros que se tornaram usuais na escola elementar norte-americana. Com o sucesso obtido no ramo da literatura 
infanto-juvenil, a Ginn \& Co. investiu na ideia precursora do livro de leitura suplementar aos manuais destinados ao aprendizado da leitura.

Em 1885, Edgar O. Silver criou a Silver \& Co. que logo se projetou pela série de impressos dedicados a novos métodos de ensino de Música, assunto de especial interesse de seu proprietário. A partir de 1886, a editora abriu-se para outras matérias, começando com a série Normal course in reading. Dois anos depois, um dos sócios vendeu a sua cota de ações a Frank W. Burdett, a partir do que a firma passou a se denominar Silver, Burdett \& Co.

Tal como ocorreria com outras, essas quatro firmas nascidas em Boston - Lee \& Shepard, D. Lothrop \& Co., Ginn Brothers e Silver, Burdett \& Co. - instalaram-se também na cidade de Nova York, entre o fim do século xix e o começo do xx, o que lhes facilitou a projeção no mercado nacional e a sequente conquista do mercado internacional.

\section{A supremacia dos livros didáticos}

São muitas as evidências que indicam os nexos, em vários níveis, entre os resultados da Guerra Civil e a crescente concentração do parque livreiro nos estados do Nordeste e do Centro-Oeste acompanhada do declínio do movimento editorial no Sul. Em outros termos: a subordinação dos separatistas do Sul - dominantemente agrário e escravagista, envolto em misticismos religiosos - aos estados do Norte - onde se gestava o tipo mais radical de cultura industrial, urbana e religiosamente pragmática, assim como se concentrava aquele especial tipo de atividade econômica que demanda tanto a disseminação das habilidades do ler e escrever, como implica a constituição da disposição mental, do desejo e do gosto de se produzir e de consumir valores abstratos. ${ }^{2}$

Assim, podem ser estabelecidos, analogamente, nexos relativamente diretos entre a expansão da escolarização por meio de instituições públicas, seguida da difusão nacional do movimento progressivista, e o crescimento vertiginoso da produção e circulação de impressos, em suas mais diferentes formas e destinações. A vantagem crescente dos títulos didáticos e de literatura infanto-juvenil sobre qualquer outra modalidade de impresso, acompanhada da enorme movimentação financeira promovida pelo comércio editorial, patenteiam esses estreitos vínculos.

Em 1798, a Teologia respondia pelo maior número de títulos (13,5\%), seguida da Literatura (11,2\%) e da "Ciência Política" (7,9\%). Os livros didáticos sequer constam das listagens norte-americanas da época, provavelmente porque, tal como ocorria em países europeus, não constituíam, à época, uma modalidade específica de impresso. Em contrapartida, Goodrich (1856) verificou que, em 20 anos - de 1778 a 1798 -, os títulos de Literatura e de Política haviam crescido em torno de 12 vezes, 
ao passo que os de Teologia aumentavam aproximadamente 6,6 vezes. ${ }^{3}$ Duas décadas depois, esse quadro havia se alterado: em 1820, os livros didáticos ocupavam o topo da lista, abarcando $30 \%$ dos títulos publicados, ao passo que os teológicos se restringiam a 6\% do total (Goodrich, 1856; Lehmann-Haupt et al., 1951).

Em meados do século xix, os títulos didáticos já haviam abocanhado $44 \%$ das edições novas, ao passo que os teológicos se reduziam a $4 \%$. Ou seja, em 30 anos, as impressões destinadas à escolarização tinham crescido 7,3 vezes, ao passo que os de Teologia quebraram o ritmo de crescimento exatamente pela metade, em comparação com o final do século anterior: cresceram apenas 3,3 vezes (Carter et al., 2006).

No que tange ao perfil educacional das diferentes regiões norte-americanas, desde o período colonial, as primeiras iniciativas partiram do Nordeste, destacadamente de Massachusetts. Em 1635, Boston abriu a primeira escola secundária ou de "gramática" ["grammar"], a Boston Latin School, financiada em parte com dinheiro oriundo de taxações públicas. Pouco depois, em 1638, próximo de Boston, foi criada a primeira universidade da América do Norte, a Harvard University. Após a independência, Massachusetts continuou liderando as iniciativas no âmbito da educação pública, e, a partir de 1837, sob a direção de Horace Mann, que formou uma linhagem de discípulos progressivistas e renovadores (Mattingly, 1981; Borrowman, 1965).

Trilhas equivalentes foram percorridas pela Pensilvânia, particularmente na Filadélfia, assim como pelos estados de Vermont, Nova York e, posteriormente, por estados do centro-oeste, tais como: Illinois, Wisconsin e Missouri. ${ }^{4}$

Essas duas regiões, Nordeste e Centro-Oeste, foram as primeiras responsáveis pelos índices de escolarização parelha de meninos e meninas desde o kindergarten ao secundário, assim como pela abertura das escolas públicas às crianças "não brancas". Segundo as estatísticas disponíveis, em 1850, 47,2\% da população estava na escola, da qual 56,2\% eram brancas e apenas 1,8\% era de "não brancas"; em 1910, esses porcentuais haviam se alterado, respectivamente, para $59,2 \%, 61,3 \%$ e $44,8 \%$ (Carter et al., 2006).

Quanto à distribuição por sexo, em 1850, 49,6\% da população masculina de crianças e jovens, e $44,8 \%$ da feminina estavam sendo escolarizados; em 1910, esses índices haviam se elevado, respectivamente, para 59,1\% e 59,4\% (Carter et al., 2006).

Seguindo a mesma tendência, em relação à população adulta e de jovens até pelo menos 14 anos de idade, os índices indicam os efeitos das iniciativas massivas de americanização efetuadas por meio da educação nas regiões urbanas - tais como Nova York, Chicago e, posteriormente, São Francisco -, para as quais se dirigiam as sucessivas ondas de migrantes vindos do campo e de imigrantes - nessa ordem: 
europeus, asiáticos e centro-americanos. Em 1870, consta que 20,0\% dos adultos e jovens até 14 anos eram iletrados, dos quais 11,5\% eram brancos e 79,9\% eram negros e de outras raças. Em 1910, esses índices se alteraram para: 7,7\%, 5,0\% e 30,5\%.

A partir de 1880, curiosamente, quando o montante de imigrações se elevou consideravelmente para refluir na década de 20 do século seguinte, as estatísticas oficiais passaram a incluir dados discriminados de "brancos nativos" e "brancos estrangeiros". Os índices registrados - uma vez que sempre incidiam nos não nativos - são menos interessantes do que a própria inclusão dessa informação para controle do Estado, posto que, naquelas décadas finais do século xix até as primeiras décadas do século $x x$ desencadeou-se o intensivo movimento denominado oficialmente de "americanismo", cujo objetivo original era o estrito ajustamento do adulto imigrante à cultura nativa, mas cujo alcance efetivo ultrapassou de muito a população-alvo. Acabou por cimentar toda uma nova cultura de tipo americanista (Tyack, 1974; Berrol, 1982; West, 1995; Leonor, 1996).

\section{A disseminação do livro didático e a construção da hegemonia de tipo americanista}

Conduzidos por elites políticas e intelectuais comprometidas com a modernização, os estados vitoriosos do Norte não amalgamaram a nova federação americana apenas impondo a sua indústria e seus mecanismos protecionistas; não operaram, portanto, no sentido de, tão somente, expandir, sem retoques, o seu projeto modernizador para o conjunto dos estados federados. Para as novas lideranças políticas e intelectuais do Norte, a vitória conquistada na guerra interna não implicou por si e em si mesma a expansão territorial de sua cultura. A forma federativa nascida do conflito civil, acrescida das sucessivas levas migratórias e imigratórias, exigiu dos vitoriosos a sua própria reordenação cultural.

Destacam-se, dentre os instrumentos utilizados para criação e difusão dessa nova cultura nacional com a qual os Estados Unidos se fundiram e se projetaram extraterritorialmente (Chodes, 2005):

1. A primazia conferida à escola, à universidade e aos impressos de diversa destinação como instrumentos de produção e difusão da nova cultura para a formação de um americano de tipo novo para uma nova sociedade;

2. a busca das acomodações pragmáticas entre os arraigados valores religiosos e os princípios da mais avançada ciência, entre a fé na democracia universal e a crença no "excepcionalismo" da nação norte-americana, entre ideologia da igualdade dos povos e a conviç̧ão de que o seu povo 
fora eleito para a salvação de si e dos demais, expressa na fórmula do “destino manifesto" (Pratt, 1927; Gutierrez, 1993; Murphy, 1999). ${ }^{5}$

Mais de 25 milhões de imigrantes instalaram-se nos Estados Unidos, entre 1870 e 1916, aumentando a população total de 40 milhões de habitantes em 1870 para mais de 100 milhões em 1916. Eram europeus fugindo das suas próprias guerras e das consequentes devastações econômicas; asiáticos e outros pobres ou empobrecidos atraídos pela rápida industrialização dos estados do Norte, pela substituição de mão de obra escrava por mão de obra imigrante no Sul, e primariamente pelo Homestead Act, ${ }^{6}$ por meio do qual lotes de terra na Região Oeste eram concedidos a baixo ou nenhum custo a quem nelas se dispusesse a trabalhar e a enfrentar ataques constantes seja dos habitantes nativos ou de foragidos da lei. Uma parcela considerável dos que haviam se dirigido, em primeiro lugar, para as plantações do Sul ou para o Oeste não suportou as precárias condições a que foram submetidos, e, tendo a sorte de sobreviver aos maus-tratos, acabaram se instalando em grandes centros. As cidades de Nova York e Chicago e suas adjacências tornaram-se, até fins da Primeira Grande Guerra, os dois maiores polos de atração dos europeus e arábes fugidos das guerras e perseguições, ao passo que os asiáticos aportavam nas costas pacíficas ${ }^{7}$ (Lanza, 1990).

Tendo de enfrentar, a um só tempo, a reconstrução do Sul - que implicava a subordinação política e moral de sua população - e as prolongadas ondas migratórias e imigratórias - que inchavam as principais cidades e as convertiam em palcos de conflagração contínua -, políticos, empresários e intelectuais que assumiram o comando da nova nação operaram sistematicamente sobre os diferentes segmentos e agregados sociais, privilegiando intervenções de tipo psicossocial e cultural. Essas intervenções programáticas geraram resultados de alcance estratégico e duração prolongada; efetuaram o que Gramsci (1999-2002) chamaria de uma "reforma intelectual e moral".

Seus melhores exemplos encontram-se na criação de escolas e instituições formativas dos mais diferentes tipos e destinações, em praticamente todos os estados da federação, nas zonas urbanas e rurais, assim como de associações, com duração mais ou menos prolongada, visando à criação do sentimento de pertencimento à comunidade e, principalmente, o ajustamento das condutas a valores morais e religiosos comuns, tanto quanto à industriosidade e ao gosto pelo consumo. $\mathrm{O}$ ensino da Língua Inglesa foi o instrumento primeiro para essa ferrenha operação de aculturação (Berrol, 1967, 1981, 1982; Tyack, 1974). ${ }^{8}$

Em meados do século XIX, os líderes do movimento em favor da escola elementar pública ${ }^{9}$ estavam convencidos de que os professores eram insuficientemente preparados para suas novas funções. Horace Mann já havia reclamado, em 1839, que os professores primários não conduziam o ensino segundo os princípios da pedagogia 
porque não haviam recebido formação adequada. Fazendo coro com outros líderes educacionais, Mann propugnava pela escola normal, onde se "combinava pura experiência com treinamento metódico" (Mattingly, 1981; Borrowman, 1965).

Até a Guerra Civil, em torno de dez estados ao Norte/Nordeste tinham criado uma ou mais escolas normais, ao mesmo tempo em que, por iniciativas privadas, outras tantas estavam sendo criadas em várias localidades.

Embora atacada pelos "puristas", como eram chamados os críticos da especialização profissional, a escola normal tornou-se o ideal máximo dos líderes progressivistas que pugnavam por salvar o ensino elementar do empirismo que pautava as práticas docentes, por meio do preparo do mestre na "arte e ciência" pedagógica (Cremin, 1954, 1957, 1961).

Embora cativantes, os argumentos em defesa da formação especializada dos professores primários e secundários geraram muitas e prolongadas controvérsias, por exemplo, quanto: 1. ao espaço a ser ocupado e à função a ser exercida pelas ciências na construção de uma nova pedagogia; 2 . à necessidade ou à possibilidade de remanescer o sentido artesanal do ato educativo; 3 . ao justo equilíbrio a ser alcançado entre o conhecimento das matérias a serem ensinadas e a destreza pedagógica para transmiti-las. Décadas depois de Horace Mann, esses dilemas levaram ao confronto de posições figuras proeminentes nos meios escolares e acadêmicos norte-americanos, tais como William H. Torris, G. Stanley Hall, John Dewey, Edward L. Thorndike e William Kilpatrick (Shapiro, 1983; Warde, 2005).

De qualquer modo, as iniciativas de criação de escolas normais foram pequenas e atraíram número pequeno de estudantes proporcionalmente à expansão das escolas públicas primárias e secundárias, acrescidas das escolas de orientação religiosa, e ao aumento vertiginoso de alunos. Em fins do século xIx, foram levantadas em torno de apenas 166 escolas normais mantidas pelos governos estaduais e 165 de iniciativa privada, e somente 70 mil estudantes matriculados, em todos os EUA.

Três décadas depois, criticadas como ineficazes, as escolas normais caminharam para a extinção, cedendo a maior parcela da formação docente aos departamentos ou às escolas de educação de nível superior (Cremin, 1954; Mattingly, 1981; Borrowman, 1965). Os institutos superiores de educação produziram relevante deslocamento nos estudos e nas pesquisas educacionais, porém, até meados do século $\mathrm{xx}$, as avaliações governamentais e as pesquisas acadêmicas davam por certo que, também eles, mostraram-se incapazes para acompanhar o crescimento quantitativo dos sistemas de ensino e fazer face à crescente complexidade das relações sociais e culturais intra e extraescolares.

Alguns intelectuais do já arrefecido movimento progressivista não precisaram de muito tempo para compreender que as reformas modernizadoras da escola 
norte-americana e a sua universalização tinham se tornado dependentes da inventividade dos editores e da capacidade de produção em larga escala das casas editoriais (Pierce, 1926; Cremin, 1957, 1959, 1961).

Nos anos de 1920 e 1930 vários artigos em revistas e jornais especializados alertavam para a magnitude atingida dos livros didáticos no interior das escolas; denunciavam, explicitamente, que os professores estavam perdendo a corrida para eles, por serem em menor número e por serem mal preparados para a função.

Em contrapartida, os escritos da época são bastante tímidos quanto aos nexos entre prevalência dos materiais didáticos e a quantidade astronômica de impressos postos em circulação desde os anos 80 do século xix até pelo menos os anos seguintes à Primeira Guerra Mundial, período em que governantes e empresários, civis e militares, donas de casa e intelectuais, católicos e protestantes se uniram em torno da bandeira do americanismo e em favor da urgente americanização dos imigrantes, $\mathrm{o}$ que, por sua vez, redundava na tarefa de americanizar cada um dos nativos.

Atuavam nas escolas, nas igrejas, nos círculos comunitários, assim como criavam clubes de mulheres, cursos noturnos de alfabetização de trabalhadores imigrantes, classes vespertinas para soldados negros em treinamento para a guerra na Europa, escolas dominicais para os ensinamentos religiosos acrianças e jovens. Também desenvolviam trabalho de conquista de meninos e meninas para o escotismo, como atraíam rapazes e moças para os cursos profissionais e as atividades esportivas oferecidos pela Associação Cristã de Moços(as) (Hopkins, 1951; Lansdale, 1956). Para os adultos, havia o Rotary Club e suas filantrópicas ações comunitárias.

Para cada uma dessas atividades, o principal instrumento de comunicação e difusão eram os impressos de diferentes formatos conforme o destinatário e a ocasião.

Eram milhões a serem atingidos, e os navios e trens não cessavam de descarregar mais e mais gente. Não havia tempo nem meios para formar milhares de professores, lideranças comunitárias e outros multiplicadores porque era preciso atingir a cada um e a todos com a palavra certa, afinada em um único diapasão.

Em suma, nos EUA, o professor já estava sendo substituído pelo livro didático nas primeiras décadas do século xx, e os editores especializados em impressos didáticos já estavam tomando o lugar dos dirigentes e intelectuais da educação.

\section{Notas}

1. Sunday School, em termos gerais, é o nome conferido às aulas que igrejas cristãs, tanto católicas quanto de diferentes denominações protestantes, mantêm (aos domingos) para instrução religiosa; são destinadas, comumente, a crianças e jovens. Em dicionários e enciclopédias religiosos consta que as ss nasceram na Inglaterra, mas ganharam considerável expansão nos EUA. 
2. Vale lembrar, em acréscimo, o contraste entre as tendências liberais da igreja presbiteriana do Norte em relação ao perfil regressivo das lideranças sulistas.

3. Os demais títulos são, por ordem decrescente, de Ciências Sociais, Medicina e Música.

4. Em 1787, quando da aprovação da Constituição que organizou a América independente, o espírito da legislação antes aprovada pelas colônias do Nordeste estendeu-se para toda a União: ficou estabelecida a criação de sistemas escolares completos em todos os estados. E a Décima Emenda Constitucional (1789) deu as bases legais para fazer da educação uma função do estado. A Primeira e a Quarta Emendas juntas garantiam a separação entre igreja e estado, transferindo, assim, o sustento da educação aos governos locais.

5. As considerações aqui apresentadas sobre a constituição do amálgama cultural norte-americano a partir da Guerra Civil (1861-1865) estão apoiadas na compreensão de que a forte unidade nacional norte-americana que deu base ao império americano implicou a hegemonia do Norte sobre o Sul pela via do que gramscianamente se poderia chamar de "consenso passivo". Ou seja, no período do término do conflito e da ocupação do Sul pelas forças político-militares do Norte, consagrado como "Reconstrução" (1865-1877), a rendição política e moral sulista deu-se pela incorporação daquela região à nação pela via econômica, na qual desempenharam papel fundamental: as malhas ferroviárias ligando as várias pontas do país; a urbanização acelerada; a migração massiva do campo para a cidade; entre outros aspectos.

6. O site http://www.archives.gov/education/lessons/homestead-act do Arquivo Nacional norte-americano oferece muitas informações e documentos originais sobre o Homestead Act de 1862.

7. Nova York foi sempre o primeiro lugar de escolha dos imigrantes europeus, uma vez que em seu porto atracavam os navios de grande calão vindos do outro lado do Atlântico; além disso, colonizada por holandeses, a cidade preservou desde seus primeiros tempos o pendor cosmopolita dos seus fundadores - que, em louvor às terras de onde partiram, chamaram a região de Novos Países Baixos e à ilha, de Nova Amsterdã, rebatizada pelos ingleses como Manhattan. Esses holandeses colonizadores transportaram para as novas plagas seus traços culturais e religiosos; eram tendencialmente liberais uma vez que entre eles havia muitos judeus e protestantes de diversas denominações, fugidos uns e outros de perseguições religiosas e políticas.

8. A historiografia norte-americana acumula centenas de trabalhos relativos aos impressos destinados ao aprendizado da Língua Inglesa. Incluem desde a etapa do aprendizado elementar do ler e escrever para crianças em processo de escolarização até o letramento de adultos, especialmente de imigrantes, passando pelas muitos métodos de ensino criados para o desenvolvimento de habilidades implicadas no aprendizado da língua nativa ou da estrangeira, bem como pelo largo espectro de gêneros didáticos, tais como: speller, reader, reading, rethoric, speeking, grammar, primer, mother tongue, language, writing, literature.

9. Nas enciclopédias de educação norte-americanas encontra-se que a public school, frequentemente, incluía os graus primário e o secundário, e algumas vezes, apenas o primário.

\section{Referências}

BERROL, S. C. Immigrants at school: New York City, 1898-1914. New York: Arno, 1967.

BERROL, S.C. The open city: jews, jobs, and schools in New York City, 1880-1915. In: Ravitch, D.; Goodenow, R. (Ed.). Educating an urban people: the New York City experience. New York: Teachers College, 1981. p. 101-115.

BERROL, S.C. Public schools and immigrants: the New York City experience. In: 
Wiess, B. J. (Ed.). American education and the European immigrant, 1840-1940. Urbana: University of Illinois, 1982. p. 30-43.

BESSIE, L. P. Public opinion and the teaching of history in the United States. New York: Knopf, 1926.

BORROWMAN, M.L. Liberal education and the professional preparation of teachers. In: Borrowman, M.L. Teacher education in America: a documentary history. New York: Teachers College, 1965. p. 1-53.

BOYER, P.S. Purity in print: the vice-society movement and book censorship in America. New York: Charles Scribner's Sons, 1968.

CARPENTER, C. History of American schoolbooks. Philadelphia: University of Pennsylvania, 1963.

CARTER, S.B. et al. (Ed.). Historical statistics of the United States, earliest times to the present: millennial edition. New York: Cambridge University, 2006.

CHODES, J.J. Destroying the Republic: Jabez Curry and the re-education of the old South. New York: Algora, 2005.

CREMIN, L.A. et al. A history of Teachers College, Columbia University. New York: Columbia University, 1954.

CREMIN, L.A. The progressive movement in American education: a perspective. Harvard Educational Review, Cambridge, Mass., v. 27, n. 4, p. 251-270, 1957.

CREMIN, L.A. What happened to progressive education? Teachers College Record, New York, v. 61, n. 1, p. 23-29, 1959.

CREMIN, L.A. The transformation of the school: progressivism in American education, 1876-1957. NewYork: Vintage, 1961.

CURTI, M. America at the world fairs, 1851-1893. The American Historical Review, New York, v. 55, n. 4, p. 833-856, Jul. 1950.

ELSON, R.M. American schoolbooks and "culture" in the nineteenth century. The Mississippi Valley Historical Review, Urbana, v. 46, n. 3, p. 411-434, Dec. 1959.

ELSON, R.M. Guardians of tradition. American schoolbooks of the nineteenth century. Lincoln: University of Nebraska, 1964.

GOODRICH, S.G. Recollections of a lifetime. Nova York and Auburn: Miller, Orton and Mulligan, 1856. $2 \mathrm{v}$.

GRAMSCI, A. Cadernos do cárcere. Rio de Janeiro: Civilização Brasileira, 1999-2002. v. 1,2 e 6. 
GUTIERREZ, D.G. Significant to whom? Mexican Americans and the history of the American West. The Western Historical Quarterly, Logan, v. 24, n. 4, p. 519-539, Nov. 1993.

HOPKINS, C.H. History of the rMCA in North America. New York: Association Press, 1951.

JENNETT, S. The making of books. Nova York: Pantheon Books, 1951.

KELLY, J. The American catalogue of books (original and reprints): published in the United States from Jan. 1861 to Jan. 1866 [1871]. New York: Wiley, 1866-1871.

KURIAN, G.T. The directory of American book publishing: from founding fathers to today's conglomerates. New York: Simon \& Schuster, 1975.

LANSDALE, H. P. A historical study of YMCA boys' work in the United States, 1900-1925. 1956. 385f. Yale University, New Haven.

LANZA, M.L. Agrarianism and reconstruction politics: the southern Homestead Act. Baton Rouge: Louisiana State University, 1990.

LEHMANN-HAUPT, H.; WROTH, L.C.; SILVER, R.G. The book in America: a history of the making and selling of books in the United States. New York: R. R. Bowker, 1951.

LEONOR, M.S. Americanization and the new immigrant, 1880-1924: a documentary history. 1996. 237f. Dissertion (PhD) - Teachers College, Columbia University, New York.

MATTINGLY, P. Academia and professional school careers, 1840-1900. Teachers College Record, New York, v. 83, n. 2, p. 219-233, 1981.

MURPHY, G. Locating the nation: literature, narrative, and the Monroe Doctrine, 1823-1904; a genealogy of American exceptionalism. Washington, DC: University of Washington, 1999.

PASKO, W.W. American dictionary of printing and bookmaking (containing a history of these arts in Europe and America, with definitions of technical terms and biographical sketches). New York: Howard Lockwood \& Co., 1894.

PIERCE, B.L. Public opinion and the teaching of history in the United States. New York: A.A. Knopf, 1926.

PRATT, J.W. The origin of "Manifest Destiny". The American Historical Review, New York, v. 32, n. 4, p. 795-798, July 1927.

PUBLISHER'S Trade List Annual (pтLA); compiled by F. Leypoldt. New York, 1874-. 
PUBLISHER'S Weekly; official organ of the Publishers' Board of Trade. New York: Bowker, 1872-76. 14v.

ROORBACH, O.A. Bibliotheca americana. New York: P. Smith, 1939.

SCHURMAN, L.C. The effect of nineteenth-century "Libraries" on the American Book Trade. In: Schurman, L.C.; Johnson, D. (Org.). Scorned literature: essays on the history and criticism of popular mass-produced fiction in America. Westport: Greenwood, 2002. p. 97-121.

SHAPIRO, M.S. Child's garden: the kindergarten movement from Froebel to Dewey. University Park: Pennsylvania State University, 1983.

STERN, M.B. (Ed.). Publishers for mass entertainment in nineteenth century America. Boston: G.K. Hall, 1980.

STRAUSS, V. The printing industry. Washington, DC: Printing Industries of America, 1967.

TEBBEL, J.W. A history of book publishing in the United States. 4 v. New York: R. R. Bowker, [1972]-1981.

TYACK, D.B. The one best system a history of American urban education. Cambridge: Harvard University, 1974.

U.S. BUREAU OF THE CENSUS/POPULATION DIVISION. Historical Census Statistics on the Foreign-born Population of the United States: 1850-1990. Washington, DC, 1999.

WARDE, M.J. Visiones de la infancia en el "child study" norteamericano: G. Stanley Hall, E. L. Thorndike y John Dewey (entre los siglos XIX y XX). In: COLOQUIO DE HISTORIA DE LA EDUCACIÓN, 13., 2005, San Sebatián. Anais... Madrid: SEDHE, 2005. p. 1-21.

WEST, L. Teacher education for americanizing immigrants in the public schools, 1871-1920: the Rhode Island normal school programs. 1995. 173f. Dissertion (PhD) - The University of Connecticut, Stanford.

WINTERICH, J.T. Early American books \& printing. Boston: Houghton, 1935.

Recebido em julho de 2009.

Aprovado em janeiro de 2010. 